\title{
Magnetic Resonance Imaging Findings of Primary Synovial Osteochondromatosis
}

\section{Primer Sinovial Os teokondramotozis te Manyetik Rezonans Görüntüleme Bulguları}

\author{
Burcu Şahin ${ }^{1}$, Elif Aktaş', Murat Arıkan², Güray Toğral ${ }^{2}$, Nazan Çiledăğ ${ }^{1}$ Emrah \\ Çağlar ${ }^{3}$, Bilgin Kadri Arıbaş ${ }^{1}$ \\ ${ }^{1}$ Dr Abdurrahman Yurtaslan Ankara Onkoloji Eğitim ve Araştıma Hastanesi, Radyoloji Bölümü \\ ${ }^{2}$ Dr Abdurrahman Yurtaslan Ankara Onkoloji Eğitim ve Araştırma Hastanesi, Ortopedi Bölümü \\ ${ }^{3}$ Bülent Ecevit Üniversitesi Radyoloji Anabilim Dalı
}

\section{ÖZET}

Giriş ve Amaç: Sinoviyal osteokondramatozis sinovial dokunun mezenkimal kalıntılarının kartilajinöz metaplazisi sonucu gelişir. Genellikle eklem aralıklarında ve tenosinoviyumda kalsifiye kartilajinöz oluşumlar ile karakterizedir. Tek eklem tutulumu yapar ve sıklıkla diz, kalça ve el bileği tutulur. Nadir de olsa kondrosarkoma malign dejenerasyon gösterebilmektedir. Patolojik olarak ispatlanmış farklı anatomik lokalizasyonlardaki sinoviyal osteokondromatozisli on olgumuza ait MR bulgularını sunmayı amaçladık. Yöntem ve Gereçler: Sinoviyal osteokondromatozis tanısı almış on olgunun MR incelemeleri retrospektif olarak iki farklı radyolog tarafından birlikte tekrar değerlendirildi. Hastaların demografik ve klinik özellikleri ve lezyonların yerleşimi, şekli, uzanımı ve MR sinyal özellikleri değerlendirildi.

Bulgular: Tanı alan 10 olgunun 6'sı erkek,4'ü kadın olup yaş ortalaması 50 bulunmuştur.(14-70 yaş) Hastaların geliş yakınmaları eklem ağrısı (n: 5), şişlik (n: 5) olarak belirtilmiştir. İki lezyon ayak bileğinde, 4 lezyon diz ekleminde, 2 lezyon omuz ekleminde ve 1 lezyon kalça ekleminde ve 1 lezyon dirsek ekleminde tespit edilmiştir. Röntgenografide tüm olguların ilgili eklem aralığında milimetrik noduler kalsikasyonlar izlenmiştir. Sadece 1 olguda kemik tutulumu da izlenmiştir. Omuz eklemi tutulumu olan olgularda ekstraartikülerbursal ve tenosinovial tutulum da izlenmiştir. Kalça eklemi tutulan olguda iliopsoas ve eksternalobturatuar bursalar da tutulmuştur. Tartışma ve Sonuç: Sinoviyal osteokondromatozisin direkt grafi ve MR bulguları genellikle tipiktir. Sinoviyal osteokondromatoziste MR intraartiküler lezyonun bursalara uzanımını ve kemik erozyonlarını göstermekte de oldukça başarılıdır.

Anahtar Kelimele r: sinovial osteokondromatosis, manyetik rezonans görüntüleme, kalsifikasyon

\begin{abstract}
Introduction: Primary synovial chondromatosis is an uncommon benign monoarticular disorder. It is characterized by proliferation and metaplastic transformation of the synovium. It is generally characterized by calcified cartilagenous structures in the joint space or in the tenosynovium. It involves one joint and knee, hip, wrist are commonly affected joints. Malignant degeneration into chondrosarcoma has been reported but is rare. Here, we aimed to present MR images of 10 patients with primary synovial osteochondromatosis. Material and Methods: We retrospectively reviewed 10 pathologically confirmed cases of synovial chondromatosis. Patients' demographics and clinical presentations were reviewed. Imaging was evaluated by two musculoskeletal radiologists with agreement by consensus. Images were evaluated for lesion location, shape, extent and signal characteristics on MR.

Results: Among the ten patients, 6 were male, 4 were female with a mean age of 50. (14-70 years) Lesion locations included knee $(n=4)$, ankle $(n=2)$, shoulder $(n=2)$, elbow $(n=1)$, hip $(n=1)$. Radiographs commonly showed milimetric nodular calcifications. Only one lesion involved adjacent bone. The two patients with shoulder involvement also involved extraarticular bursa and tenosynovium. The case with the hip involvement also involved iliopsoas and external obturator bursa.

Discussion and Conclusion: The radiographic and magnetic resonance imaging findings of synovial osteochondromatosis is typical. MRI is successful in determining the bone erosions and bursal extent of the intraarticular lesion.

Keywords: synovial osteochondromatosis, magnetic resonance imaging, calcification
\end{abstract}




\section{Giriş}

Sinoviyal osteokondromatozis sinoviyal dokunun mezenkimal kalıntılarının kartilajinöz metaplazisi sonucu gelişir. Genellikle eklem aralıklarında ve tenosinoviyumda kalsifiye kartilajinöz oluşumlar ile karakterizedir. Tek eklem tutulumu yapar. S1klıkla diz ve kalça eklemi tutulur. Sinovyumun uzandığı bursa ve tendonlar boyunca da görülebilir ve tenosinoviyal, bursal osteokondromatozis olarak adlandırılır. Primer ve sekonder formları vardır. Sekonder formu osteoartrit gibi eklem patolojileri ile ilişkilidir. Primer osteokodromatozis 3-5. dekatta ve erkeklerde daha sık görülmektedir. Ağrı, şişlik, hareket k1sitlılığı en sik görülen semptomlardır. Görüntüleme bulguları genellikle spesifiktir. Radyografide halkasal kalsifikasyon gösteren çok sayıda intraartiküler kondral cisimler görülmektedir. Ekleme komşu kemik yüzlerde ekstrinsik erozyon görülebilir $(1,2)$. Nadir de olsa kondrosarkoma malign dejenerasyon gösterebilir. $\mathrm{Bu}$ makalede, patolojik olarak ispatlanmış farklı anatomik lokalizasyonlarda görülen sinoviyal osteokondromatozisli 10 olgumuza ait manyetik rezonans görüntüleme (MRG) bulgularını sunmayı amaçladık .

\section{Gereç ve Yöntem}

Patolojik olarak tanı almış sinoviyal osteokondromatozisli on olgunun MR incelemeleri retrospektif olarak iki farklı radyolog tarafindan birlikte tekrar değerlendirildi. Tüm vakalar $1.5 \mathrm{~T}$ manyetik alan gücüne sahip tarayıc1 tarafindan gerçekleştirilmiştir (GE Excite Scanner, GE Healthcare Technologies, Waukesha, Wis). Tüm taramalarda standart protokol uygulanmış olup en az bir planda T1 (TR/TE, 900/7ms) ve T2 (TR/TE 2740/42ms) ağırlıklı spin eko sekansları elde edilmiştir. Kesit kalınlığ $4 \mathrm{~mm} / 0.5 \mathrm{~mm}$, görüntüleme matriksi 256x128, eksitasyon sayıs1 1-2, görüntüleme alanı taranan alana göre değişmekte olup 16$40 \mathrm{~cm}$ arasında belirlenmiştir. Taranacak bölgeye göre incelemelerde yüzeyel ve vücut sarmalları kullanılmıştır. Hastaların klinik özellikleri, lezyonların yerleşimi, şekli, kalsifikasyon varlığı, kemik tutulumu, bursaltenosinoviyal uzanımları ve MR sinyal özellikleri değerlendirildi.

\section{Sonuçlar}

Ocak 2013 ve Mart 2016 tarihleri arasında patolojik olarak sinoviyal osteokondromatozis tanısı almış on hastanın 6'sı erkek, 4'ü kadın hasta olup yaş ortalaması 50 bulunmuştur. Hastaların geliş yakınmaları eklem ağrısı (n:5), şişlik (n:5) olarak belirtilmiştir. İki lezyon ayak bileğinde, 4 lezyon diz ekleminde, 2 lezyon omuz ekleminde, 1 lezyon kalça ekleminde ve 1 lezyon dirsek ekleminde tespit edilmiştir. Röntgenogramlarda tüm olguların ilgili eklem aralığında milimetrik noduler kalsikasyonlar izlenmiştir. Sadece 1 olguda omuz eklemi ile birlikte glenoid kemik tutulumu da izlenmiştir. Her iki omuz eklemi tutulumu olan olgularda ekstraartiküler bursal ve tenosinoviyal tutulum da izlenmiştir. Kalça eklemi tutulan olguda iliopsoas ve eksternal obturatuar bursalar da tutulmuştur. MRG'da sekiz olguda sinoviyal hipertrofi, sinoviyal kontrastlanma ve hipointens kartilajinöz cisimler izlenmiştir (Resim 1-2). İki olguda sadece kartilajinöz cisimler izlenmiştir.

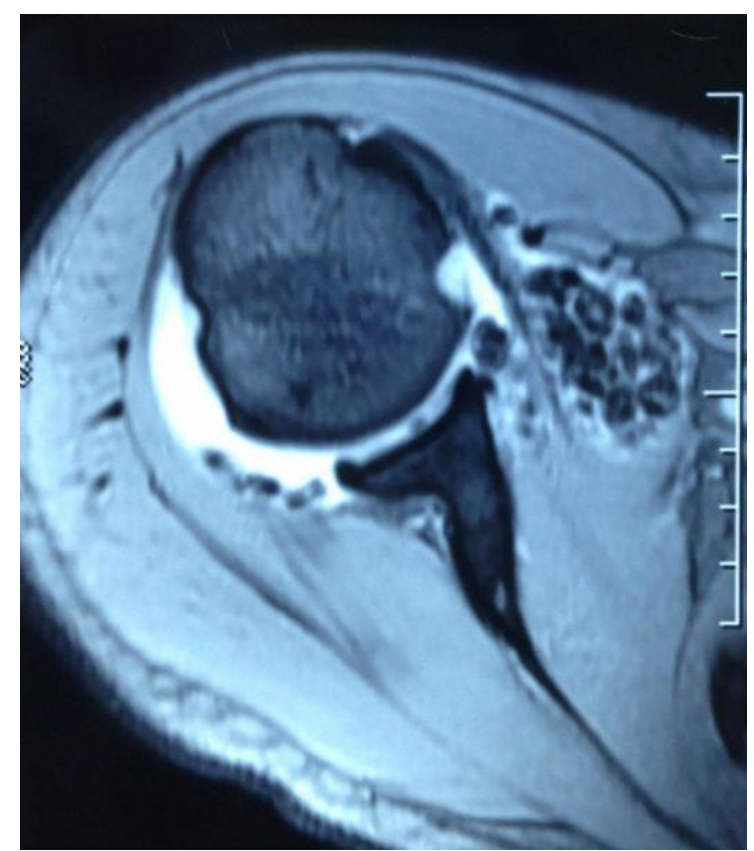

Resim 1: Omuz eklemi aksiyal MR görüntüsünde eklem düzeyinde milimetrik kartilajenöz cisimler 


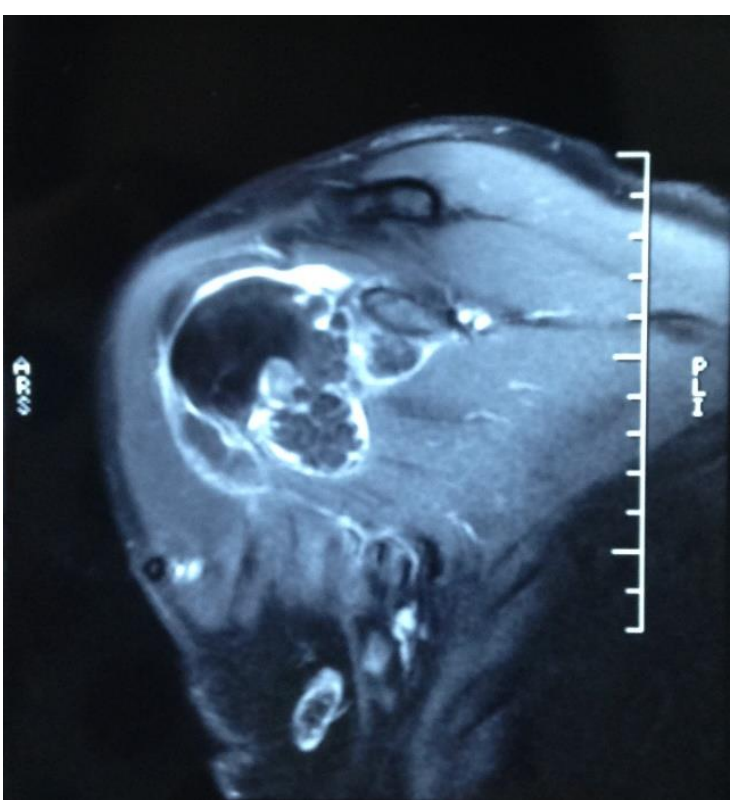

Resim 2: Omuz eklemi koronal MR görüntülerinde eklem düzeyinde milimetrik kartilajenöz cisimler

\section{Tartışma}

Sinoviyal osteokondromatozis etyolojisi bilinmeyen, sinoviyumun proliferasyonu ve metaplastik değişimi ile karakterize benign bir süreçtir. Nadiren spontan regresyon gösterebileceği bildirilmiştir (1).

Radyografide eklem aralığ 1 içerisinde çok sayıda şekil olarak birbirine benzer noduler kalsifikasyonlar patognomoniktir. Halka-yay tarzı mineralizasyon tipiktir. Eklem aralığında sıvı artış1 görülebilir. Ekleme komşu kemik yüzlerde ekstrensek erozyon görülebilir. Ekstrensek erozyon agresif sürece işaret edebilir. \%5-30 olguda radyografi normal olabilir. Bilgisayarlı tomografi (BT), kalsifikasyonların tespit ve karakterizasyonu ile ekstrensek erozyonu göstermek için en uygun modalitedir $(1,2)$. Ancak üstün yumuşak doku kontrastı ve multiplanar tarama kapasitesi nedeniyle sinoviyal patolojilerin değerlendirilmesinde MR daha üstün bir modalitedir.

Kramer ve arkadaşları, yaptığı bir çalışmada primer sinoviyal osteokondramatozisin MR'da 3 ayrı radyolojik paternini tanımlamışlardır (3). Bu paternler Milgramın tanımladığı histopatolojik gradeleme ile koreledir (4). Milgram'ın tanımladığı histopatolojik evrelemeye göre birinci evrede aktif sinoviyal hastalık mevcuttur, ikinci evrede aktif sinoviyal hastalık ile birlikte eklem fareleri bulunur, üçüncü evrede ise sadece eklem fareleri görülür. MR da en sık görülen patern Milgramın ikinci fazıdır. $\mathrm{Bu}$ fazda $\mathrm{T} 1$ ağırlıklı görüntülerde kas ile izointens T2 ağırlıklı görüntülerde hiperintens sinyal özelliğinde lobule, homojen görünümde intraartiküler yumuşak doku ve tüm fazlarda hipointens eklem fareleri izlenmektedir. Bizim olgularımızın tümünde eklem fareleri izlenmekte olup 8 vakada sinoviyal bulgular eşlik etmekteydi. Dolayısıyla bu seride de literatürle uyumlu olarak sinoviyal osteokondromatoziste en s1k, kartilajinöz cisimlerle sinoviyal bulguların birlikte izlendiği görülmüştür.

Sinoviyal osteokondromatozisin röntgenografi ve MRG bulguları genellikle tipik olmakla birlikte nadir de olsa non-mineralize ekstraartiküler manifestasyonları da olabilir (16). MR intraartiküler lezyonun bursalara uzanımını ve kemik erozyonlarını göstermekte de oldukça başarılıdır. Ayrıca bazen röntgenografi ve BT'de görülemeyen kondral cisimleri uzun TR değerlerinde kum taneleri şeklinde görmek mümkün olabilmektedir. Bizim de omuz eklemi tutulan bir olgumuzda glenoid kemik tutulumu MRG incelemede tespit edildi. Ayrıca yine omuz ve kalça eklemi tutulumu olan vakalarımızdaki ekstraartiküler bursal tutulumlar da MRG'da tespit edilebildi.

Sinoviyal osteokondromatozisin radyolojik bulguları oldukça tipik olmakla birlikte ayırıcı tanıda pigmente villonoduler sinovit, sinoviyal hemanjiyoma, lipoma arboresens, sinoviyal kondrosarkom ve siderotik sinovit düşünülmelidir.

Primer sinoviyal osteokondromatozis tedavisi cerrahi rezeksiyondur. Geniş serilerle yapılan çalışmalarda rekürrens oranı \%3-23 arasında değişmektedir. Rekürrensin çoğunlukla yetersiz rezeksiyona sekonder olduğu düşünülmektedir $(5,6)$.

Malign transformasyon oran $1 \% 5$ olarak bildirilmiştir. Rekürren primer sinoviyal osteokondramatozis ve kondrosarkom malign transformasyonu benzer radyolojik özellikler gösterebilir. Çevre yumuşak dokuya, bursalara uzanım ve ekstrinsik kemik erozyonu her iki durumda da görülebilir. (1-4)

Bertoni ve arkadaşlarının belirttikleri gibi gerçek kortikal destrüksiyon ile birlikte kemik iliği invazyonu malignite işareti olarak 
düşünülmelidir. Kemik iliği invazyonunu göstermede en başarılı yöntem MRG'dır(7).

Sonuç olarak, sinoviyal

osteokondromatozis tipik radyolojik bulgulara sahiptir. Çoğu zaman röntgenografi tek başına hastalığı tanımaya yeterli olmaktadır. BT kalsifikasyonların varlığını ve eşlik eden kemik erozyonunu göstermede önemlidir. MRG lezyonun ekstraartiküler yayılımı dışında malign transformasyon takibi açısından da gereklidir.

\section{Referanslar}

1. Murphey MD, Vidal JA, Fanburg-Smith JC, Gajewski DA. Imaging of synovial chondromatosis with radiologic-pathologic correlation. Radiographics. 2007;27(5):1465-88.
2. Kim SH, Hong SJ, Park JS, Cho JM, Kim EY, Ahn JM, Park YS. Idiopathic synovial osteochondromatosis of the hip: radiographic and MR appearances in 15 patients. Korean J Radiol. 2002 ;3(4):254-9.

3. Kramer J, Recht M, Deely DM, et al. MR appearance of idiopathic synovial osteochondromatosis. J Comput Assist Tomogr 1993;17:772-776.

4. Milgram JW. Synovial osteochondromatosis: a histopathological study of thirty cases. J Bone Joint Surg Am 1977;59:792-801.

5. Rasheed S, Peh WC, Chin TW. Clinics in diagnostic imaging (122). Singapore Med J. 2008 ;49(5):430-3; quiz 434.

6. Wittkop B, Davies AM, Mangham DC. Primary synovial chondromatosis and synovial chondrosarcoma: a pictorial review. Eur Radiol. 2002 ;12(8):2112-9.

7. Bertoni F, Unni KK, Beabout JW, Sim FH. Chondrosarcomas of the synovium. Cancer 1991; 67:155-162. 